\title{
Implementation of vehicle ventilation system using NodeMCU ESP8266 for remote monitoring
}

\author{
Amirun Murtaza Abd Jalil ${ }^{1}$, Roslina Mohamad², Nuzli Mohamad Anas ${ }^{3}$, Murizah Kassim4, \\ Saiful Izwan Suliman ${ }^{5}$ \\ 1,2,4,5 Faculty of Electrical Engineering, Universiti Teknologi MARA, 40450 Shah Alam, Selangor, Malaysia \\ ${ }^{3}$ Wireless Innovation, MIMOS Berhad, 57000 Kuala Lumpur, Wilayah Persekutuan, Malaysia
}

\section{Article Info}

Article history:

Received Mar 24, 2020

Revised May 27, 2020

Accepted Jul 11, 2020

\section{Keywords:}

Embedded controller

Internet of things

NodeMCU ESP8266

Remote monitoring

Temperature and rain sensors

Vehicle ventilation

\begin{abstract}
In this paper, an implementation of vehicle ventilation system using microcontroller NodeMCU is described, as an internet of things (IoT) platform. A low-cost wireless fidelity (Wi-Fi) microchip ESP8266 integrated with NodeMCU provides full-stack transmission control protocol/internet protocol (TCP/IP) to communicate between mobile applications. This chip is capable to monitor and control sensor devices connected to the IoT platform. In this reserach, data was collected from a temperature sensor integrated to the platform, which then monitored using Blynk application. The vehicle ventilation system was activated/deactivated through mobile application and controlled using ON/OFF commands sent to the connected devices. From the results, the vehicle ventilation system built using NodeMCU microcontroller is capable to provide near real-time data monitoring for temperature in the car before and after the ventilation system was applied.
\end{abstract}

This is an open access article under the CC BY-SA license.

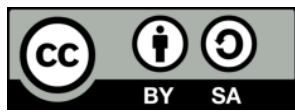

\section{Corresponding Author:}

Roslina Mohamad,

Faculty of Electrical Engineering,

Universiti Teknologi MARA,

40450 Shah Alam, Selangor, Malaysia.

Email: roslina780@uitm.edu.my

\section{INTRODUCTION}

In the era of information technology, internet of things (IoT) helps many devices to stay connected. With the help of the internet network, every smart device can communicate with each other. Internet is used everywhere from small mobiles till high end data servers. There are many types of devices which can be accessed or connected using IoT [1-3] such as smart television (TV), smart speaker, toys and smart appliances. The IoT has created the revolution all over the world and fascinatingly it has become integral part of life $[4,5]$. There are several examples of IoT applications such as IoT for connected home [6], smart cities, industrial automation [7, 8], retail, healthcare [9], agriculture [10, 11] and automotive.

An intelligent vehicle security framework empowers user to control vehicle naturally without any limitation. Various security with the basic apparatuses or advancement equipments have been produced in the vehicle to respond to the vehicle burglaries today. For instance, keys to the four-wheel vehicles were designed as the standard security $[12,13]$. Authors in [14] combined the global positioning system (GPS) technology and IoT phrasing by utilizing an arduino microcontroller. In [15], security frameworks for vehicles was created by designing tracking systems utilizing few sensors arrange modernization, and in [16] a security framework was built utilizing global system of mobile (GSM) network and multimedia messaging service (MMS) or short message service (SMS) to track missing vehicles. Furthermore, the alert feature can be provided, for example using SMS among many other technologies [17, 18]. 
In this paper, the implementation of a vehicle ventilation system using microcontroller NodeMCU is presented. The idea is to develop an IoT application framework consisting wireless link in order to connect to a cloud server. An alert messaging system is integrated to the framework to provide real-time monitoring and controlling the vehicle's sensor devices. The rest of this paper is organized as follows: Section II provides literature review of several similar IoT applications, as well as defining the scope of the vehicle ventilation system framework. Section III describes the hardware and software design implemented in this IoT platform. The results of the monitoring and alert system of the vehicle ventilation system are discussed in Section IV, while the concluding remarks were given in the end.

\section{LITERATURE REVIEW}

The entire IoT system must have properties such as confidentiality, integrity, authentication, authorization, availability and privacy to guarantee security in IoT [19, 20]. Figure 1 depicts the major challenges in enhancing security in IoT environment. This section provides review on the security aspects implemented in two IoT applications, specifically vehicle and home security system.

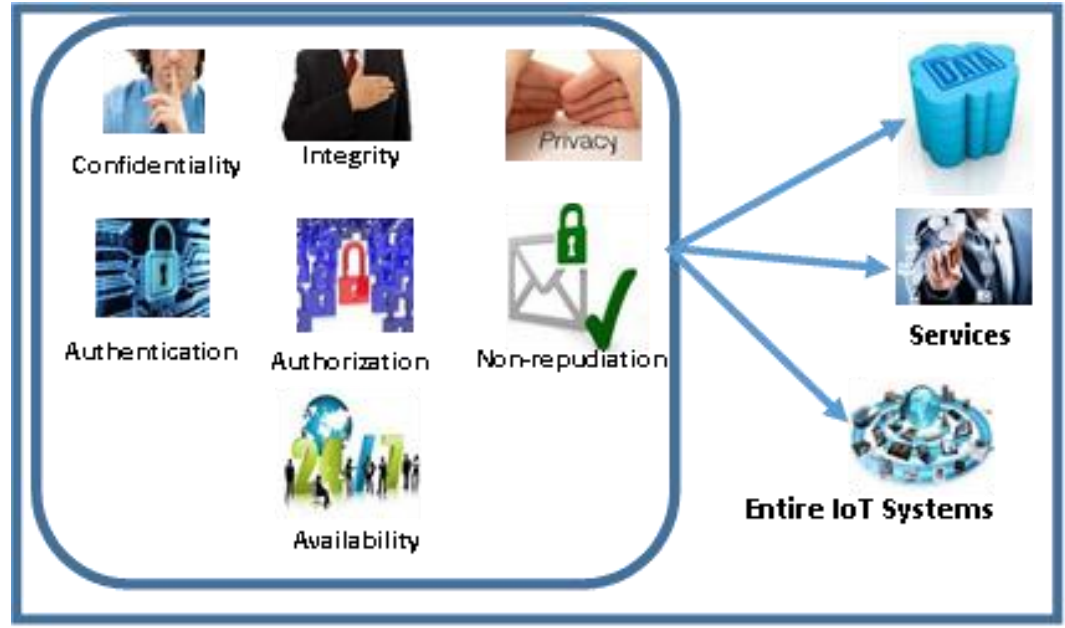

Figure 1. Security issues in IoT system [19]

\subsection{Vehicle alert system}

Vehicle alert system with tracking capability and identifying the car theft utilizing the comprehensive system for mobile communications such as using global system of mobile GSM and the global positioning system (GPS) technologies in Raspberry Pi $[16,18]$. The system was a framework that expanded vehicle security, as it tracked area of the lost vehicle, and enable authority to had trustworthy proof that the vehicle was stolen. The task utilized the GSM and the GPS technology, which incorporated the utilization of wireless local area networking (WLAN or Wi-Fi) module, Raspberry Pi camera, sensors, android phone and Raspberry Pi as its essential segments. The owner received an alert, when the vehicle was moved in the lock mode through Wi-Fi module connected to the Raspberry Pi kit which was kept inside the vehicle. It also integrated a Raspberry Pi camera that take pictures when the vehicle was lock or unlock mode and gyro sensor that measured or maintained the orientation. The system gave the solution for tracking and identifying the vehicle by giving an alert in the web page with face recognition. Figure 2 shows the system diagram of the vehicle security system with tracking capability using GSM and GPS technologies.

Authors in [21] focused on the method and performance of a microcontroller based smart car security system with SMS or utilizing portable application intrusion alert capability. In the event that the auto entryway was wrongly opened or the auto was vibrated, an alert flag proposed and it sent SMS message to the owner's mobile phone quickly. A micro-controller Arduino Uno R3, radio frequency identification (RFID) reader, RFID label data and a GSM modem were used for the hardware implementation of the system. The satellite recognized the closeness of a GPS recipient and transmitted data in National Marine electronics association (NMEA) organize and global positioning system fix or accuracy data (GGA). The data was then process into Arduino Uno R3. Output subsystem comprised of minimum output, relay action and GSM communication subsystems. There were light-emitting diode (LED) and buzzer on minimum 
output subsystems as pointers that showed the data and a liquid-crystal display (LCD) to demonstrate the data watcher yield. Figure 3 shows the block diagram of an smart vehicle security system.

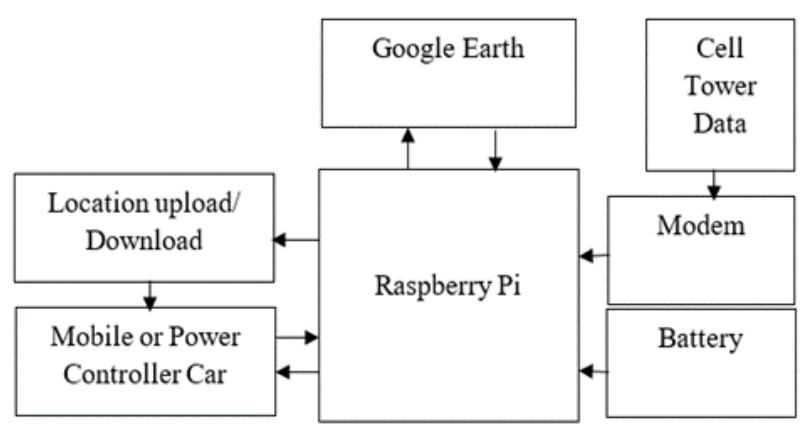

Figure 2. System diagram of the vehicle security system using GSM and GPS technologies [16]

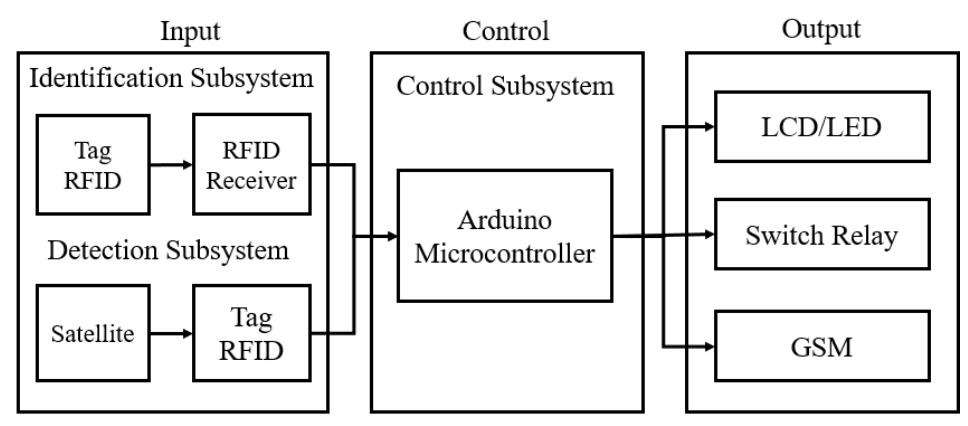

Figure 3. Block diagram of a smart vehicle security system [21]

\subsection{Home alert system}

Design and implementation of Raspberry Pi based monitoring and controlling home automation system from an android application has been presented in [22]. This system used Wi-Fi technology to connect the system components between the internal network communication and external network communication. Android application in smartphone acted to give orders to the units to control the home appliances. Raspberry Pi functioned to coordinate the sensors and appliances of a home automation system and communicated it with android application through wireless technology. Python was used and written in the system for running the server on Raspberry Pi device. The objective of this system was to reduce the total energy consumed by the home appliances.

Authors in [23] presented a system for the users to control home electronic appliances with the security system using mobile platform. Internet network helped the devices to be controlled in the Raspberry Pi micro-controller. The micro-controller board received commands (orders) sent by the user from an android mobile application to turn home appliances ON and OFF. This user-friendly android application had several buttons to control the appliances remotely. The Raspberry Pi connected to the home appliances using relays and a communication module interfaced to a cloud service of Microsoft azure. To connect with Raspberry Pi's general purpose input output (IO) pins, the Python GPIO library provides the interface to the IoT platform, such that the ON or OFF states were controlled by the Raspberry Pi through an electromagnetic relay. The objective of this system was to optimize the energy consumption based on the calculation of the total power consumption of the home appliances that had been made. Figure 4 shows the system diagram for Raspberry Pi subsystem remote control using android application.

An algorithm for smart home automation system based on IoT using sensor nodes was proposed in [24], which were directly connected to Arduino Nano. The user turned ON or OFF the lights based on the motion sensor and the alarm generated based on the gas sensor. The communication was interfaced between the Arduino Mega and web server to monitor the power consumption of different home appliances. This home automation system helps to provide a low cost and efficient solution to the users. The results showed that the system was able handle to control and monitor the function of home. The energy consumption flow of real time algorithm for the smart home automation based on the IoT is shown in Figure 5.

Implementation of vehicle ventilation system using NodeMCU ESP8266 for... (Amirun Murtaza Abd Jalil) 


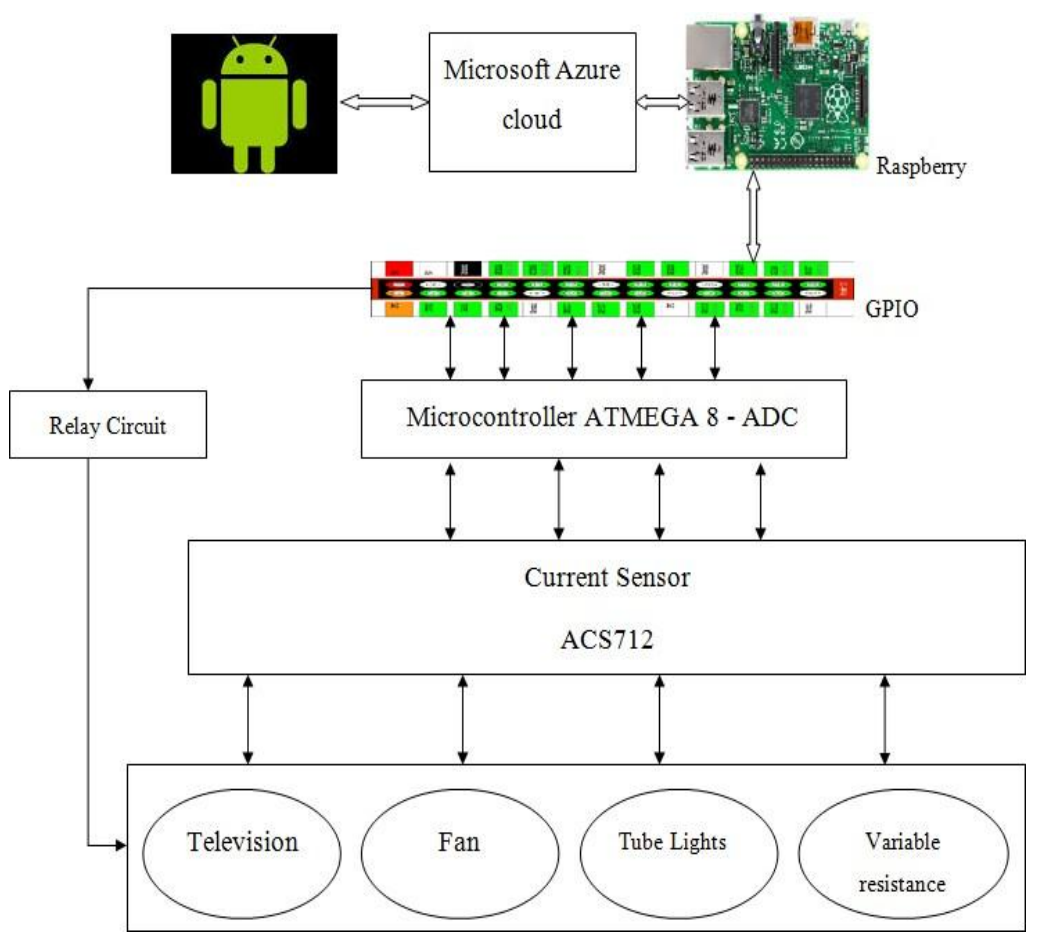

Figure 4. System diagram for Raspberry Pi remote control using android application [23]

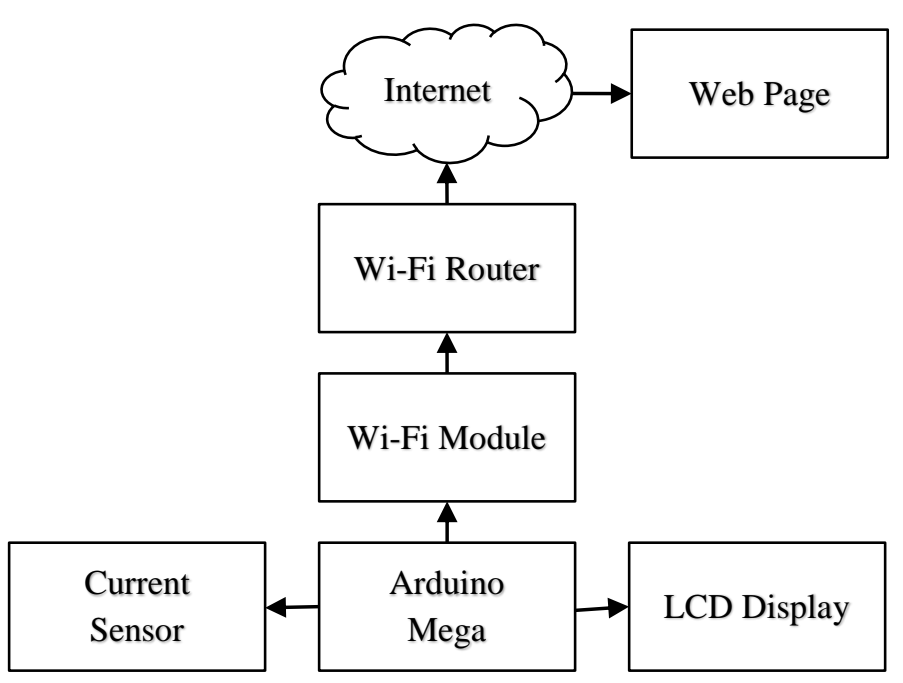

Figure 5. The energy consumption flow of real time algorithm for the smart home automation [24]

\section{SYSTEM DESIGN AND IMPLEMENTATION}

The vehicle ventilation system utilized microcontroller based on the NodeMCU ESP8266, connected to sensors as well as the vehicle accessories. It was connected to Wi-Fi in order to store the sensed data in a cloud server $[10,25]$. As depicted in Figure 6, DHT11 and rain sensor were connected to the microcontroller to sense the temperature in the vehicle and to detect rain. Then, the vehicle accessories such as power window and fan were controlled via a mobile device. The relay and motor were connected as the actuator to the fan and vehicle power window, respectively, powered using $12 \mathrm{~V}$ voltage. Figure 7 depicts the actual setup.

Blynk, a hardware-agnostic IoT platform had been integrated in this vehicle ventilation system. It can control supported hardware remotely, stored the sensed data and visualize it with built-in tools. Figure 8 (a) depicts the components provided in the Blynk to develop a mobile application. Button, slider 
and timer are among of the widgets available in the application. Figure 8 (b) gives an example to configure the setting of Button Widget. The output pin was configured to link up using Android development software installed in the NodeMCU ESP8266. A Firebase Library installed in the Android to provid cloud services to the mobile application. As shown in Figure 9, Firebase provides functionality like analytics, databases, messaging and crash reporting which are recommended for future work.

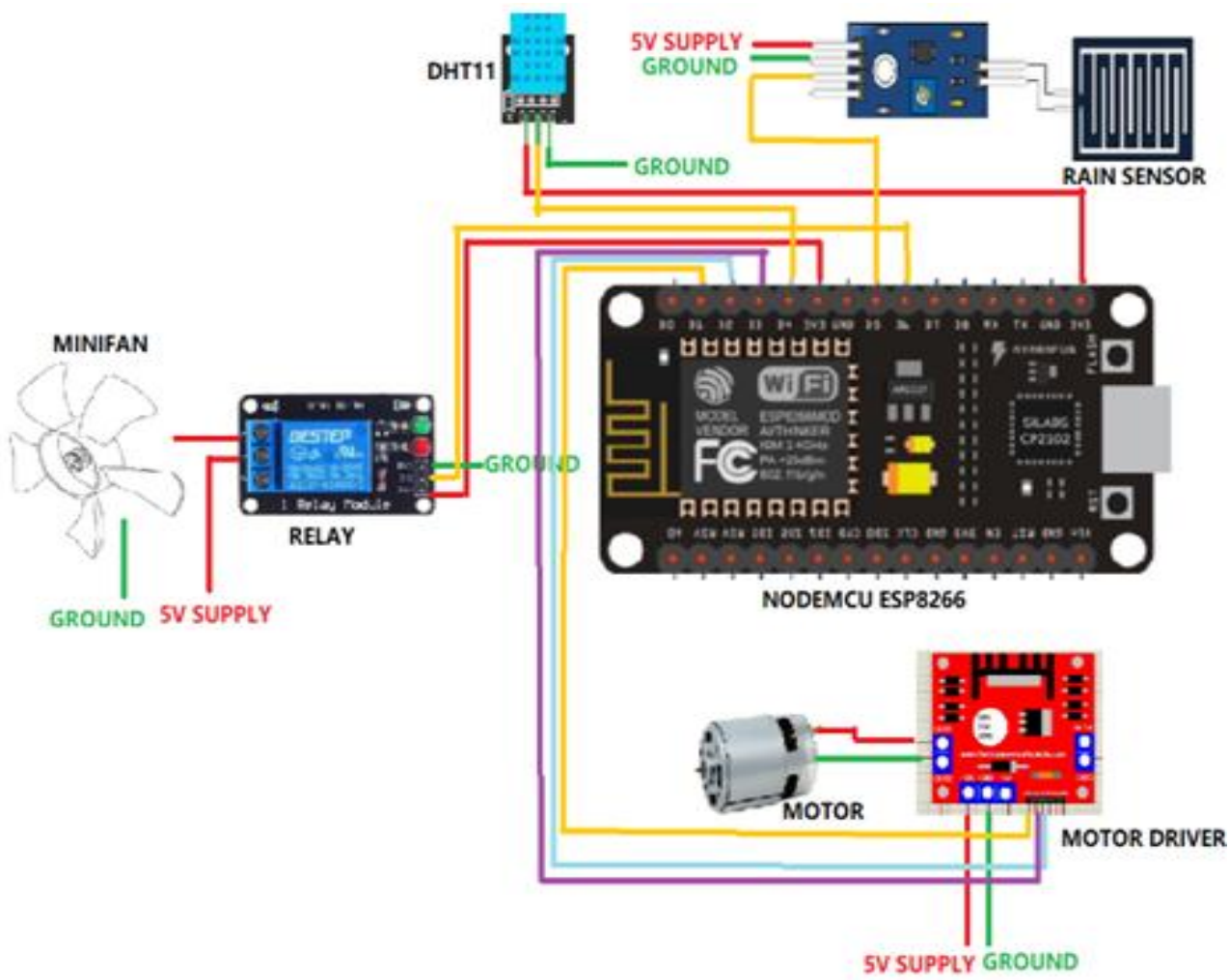

Figure 6. The vehicle ventilation system connection

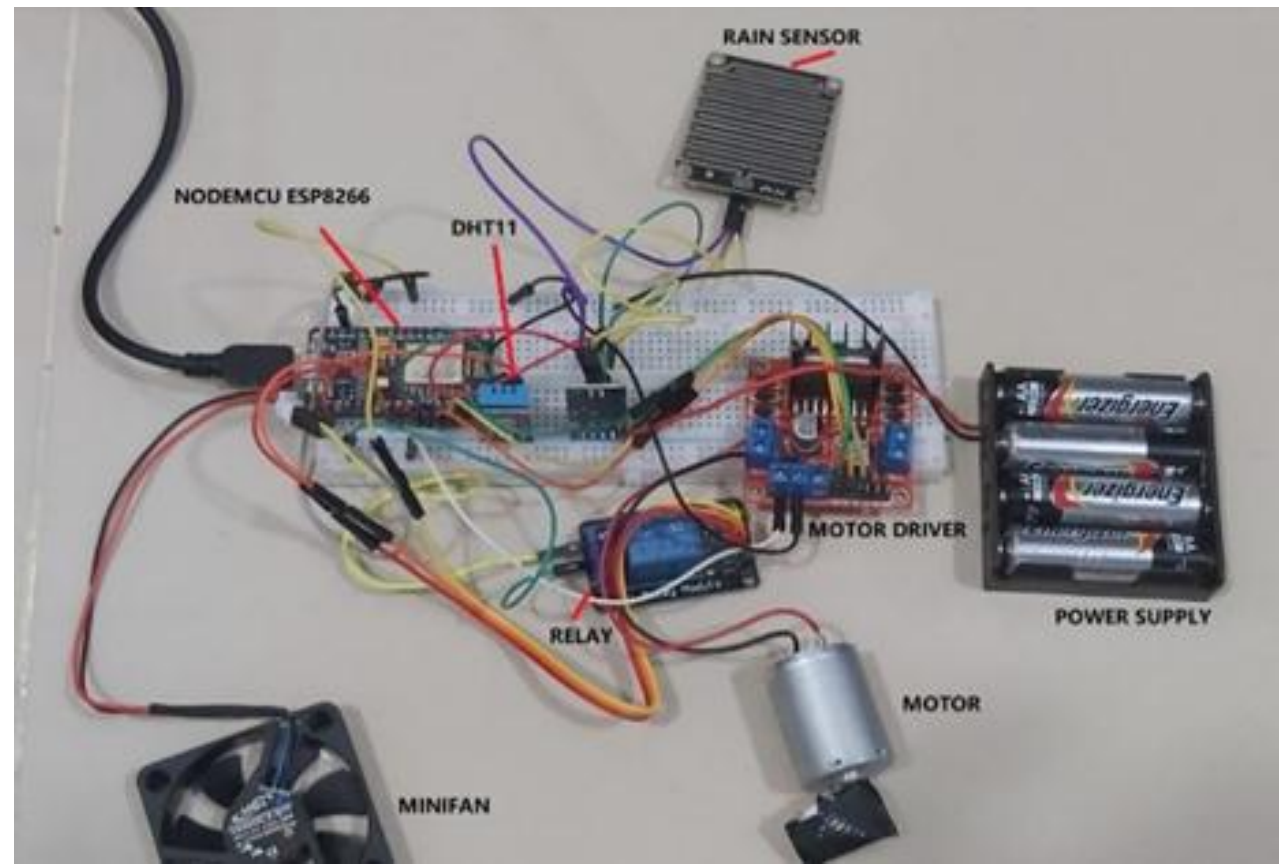

Figure 7. Hardware construction and testing 


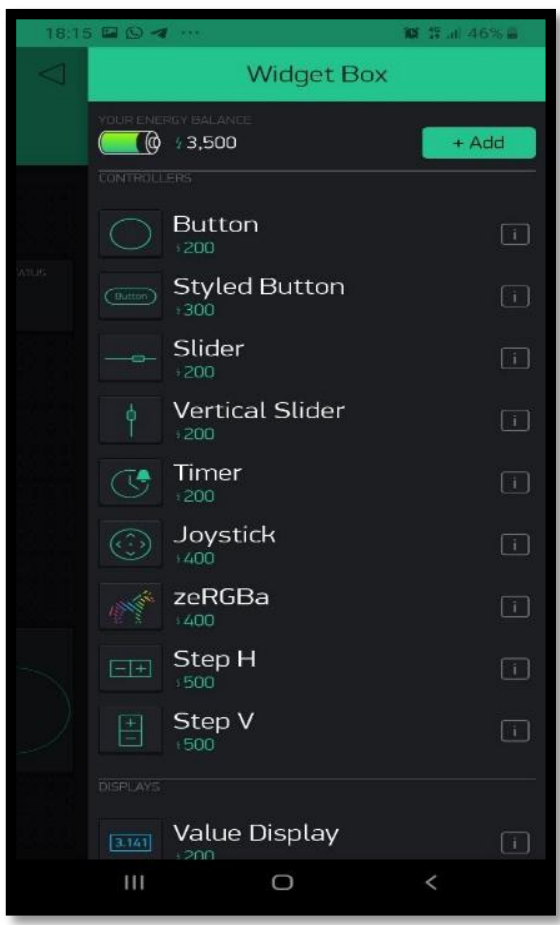

(a)

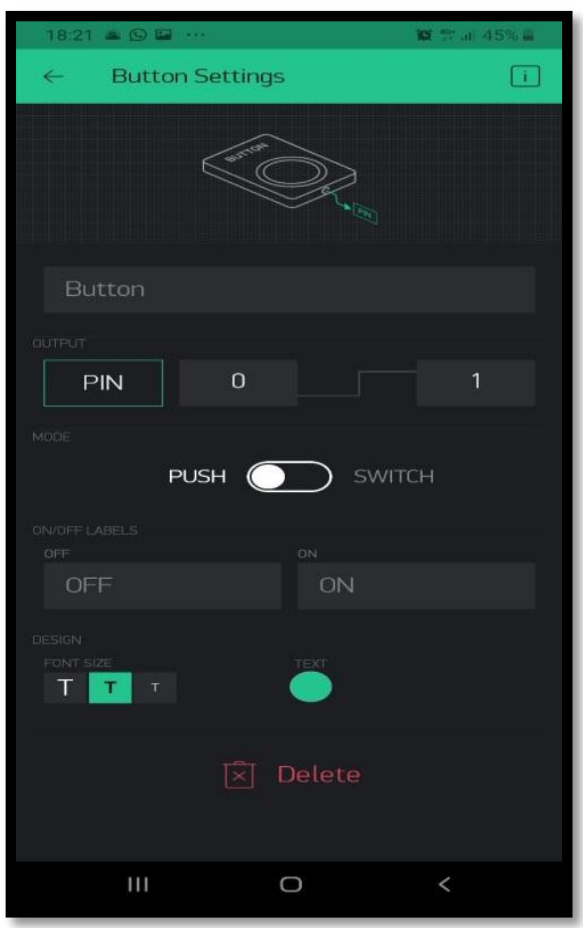

(b)

Figure 8. Blynk application, (a) Components of the widget box, (b) Settings of button widget

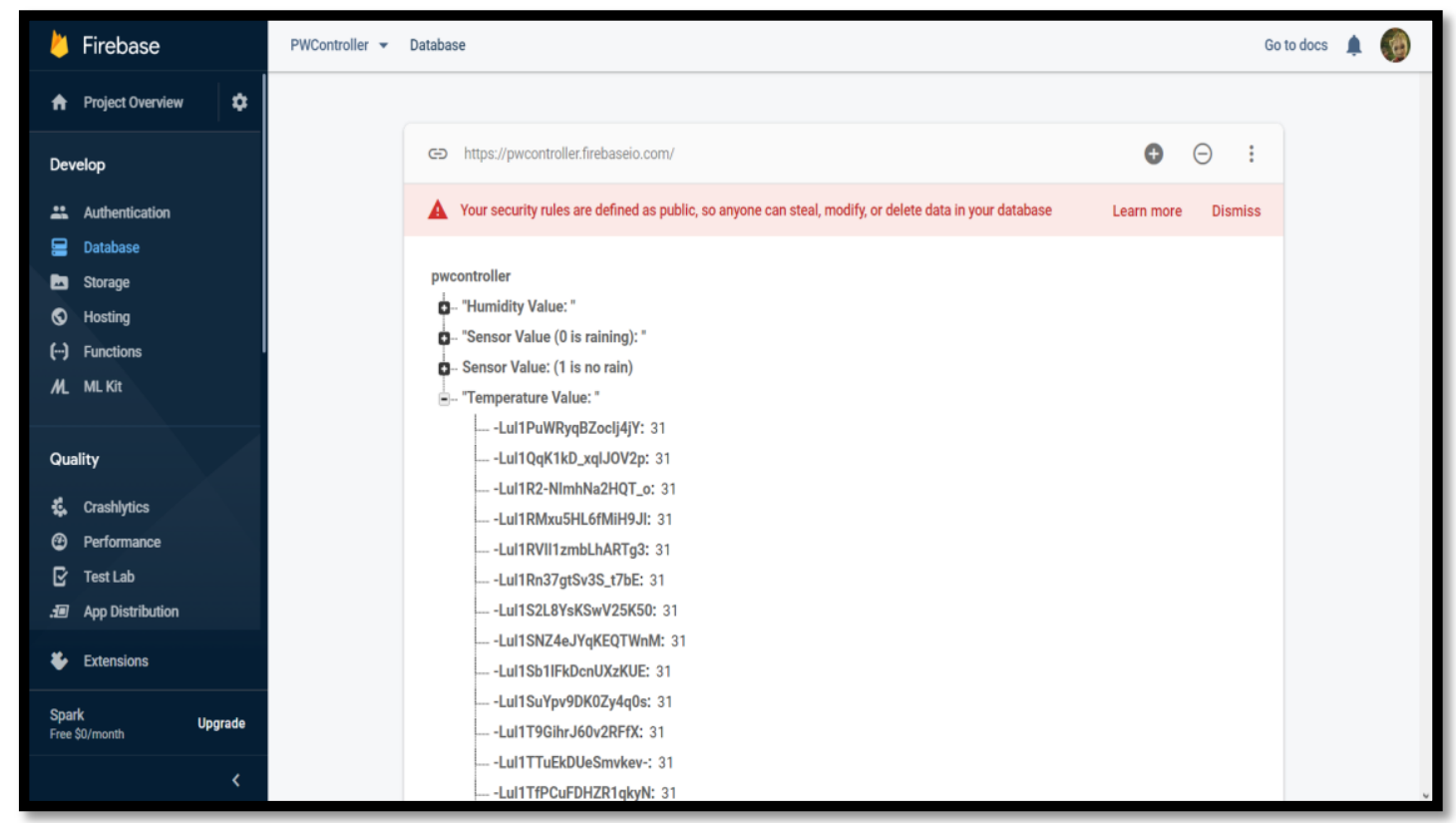

Figure 9. The firebase platform

\section{SYSTEM MONITORING AND PRESENTATION}

A mobile application was developed for the vehicle ventilation system that includes an alert messaging system. The mobile application was developed using Blynk while the measured data from the temperature sensors were presented in the Reading Temperature page, as shown in Figure 10 (a). 
Figure 10 (b) shows the Control Accessories page, as defined, to control the vehicle accessories connected to the NodeMCU controller. Notifications were sent to the mobile plaltform whenever the temperature exceeds a pre-defined threshold and/or rain starts to fall. These would allow the users to control the vehicle accessories according to the received notifications. Figures 11 (a) and (b) depict the notification when the temperature exceeds $35{ }^{\circ} \mathrm{C}$ and when rain starts to fall.

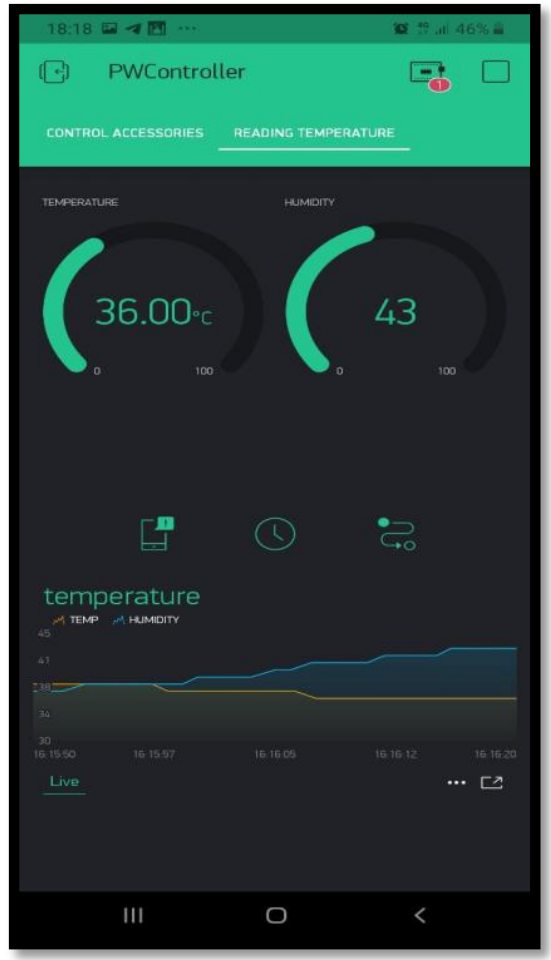

(a)

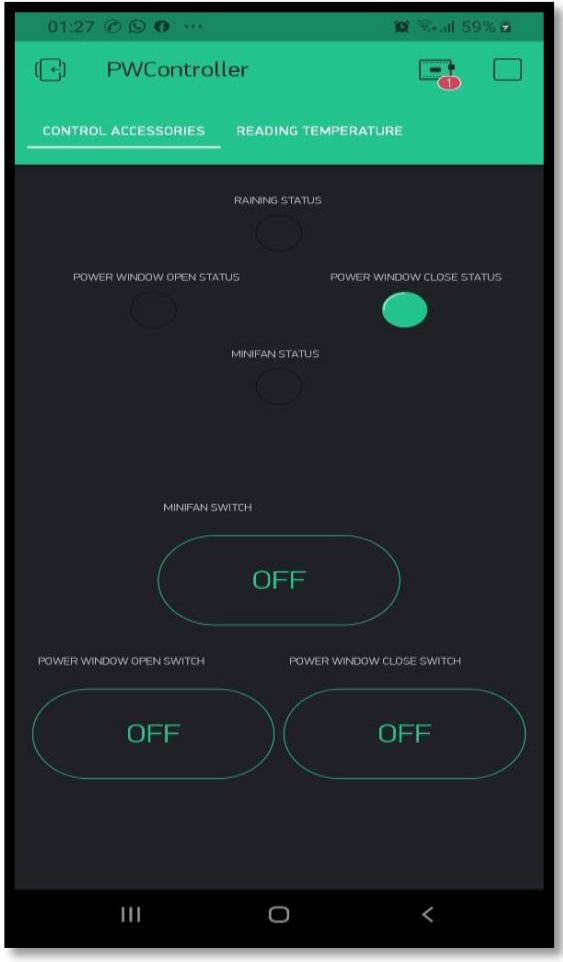

(b)

Figure 10. The blynk platform, (a) Reading temperature page, (b) Control accesorries page

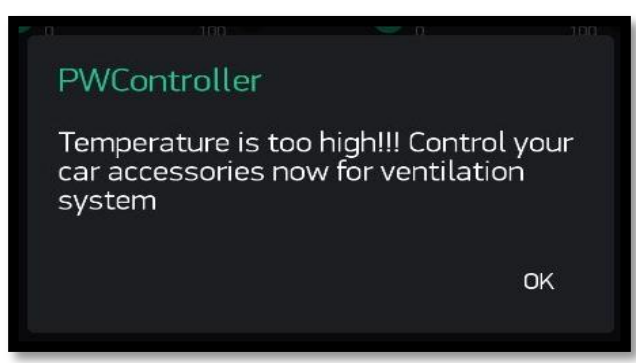

(a)

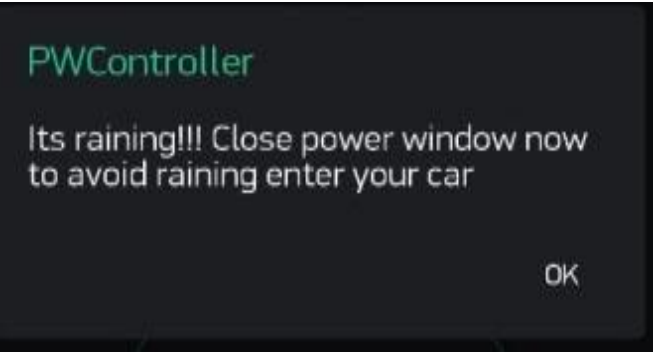

(b)

Figure 11. Alert messaging system

Graph in Figure 12 presents the results obtained by collecting the temperature reading in a vehicle. The average temperature before the ventilation system in the morning is $28.5^{\circ} \mathrm{C}$ while after the ventilation, its average is $24.2^{\circ} \mathrm{C}$ which about $4.3^{\circ} \mathrm{C}$ difference. In the noon, the average temperature is $51.2^{\circ} \mathrm{C}$ before the ventilation system and $38.8^{\circ} \mathrm{C}$ after the ventilation which about $12.4^{\circ} \mathrm{C}$ difference. The average temperature stated that in evening is $40.4^{\circ} \mathrm{C}$ while is $33.3^{\circ} \mathrm{C}$ after turning on the ventilation system with $7.1^{\circ} \mathrm{C}$ difference. The temperature is reduced about $19.8 \%$. 


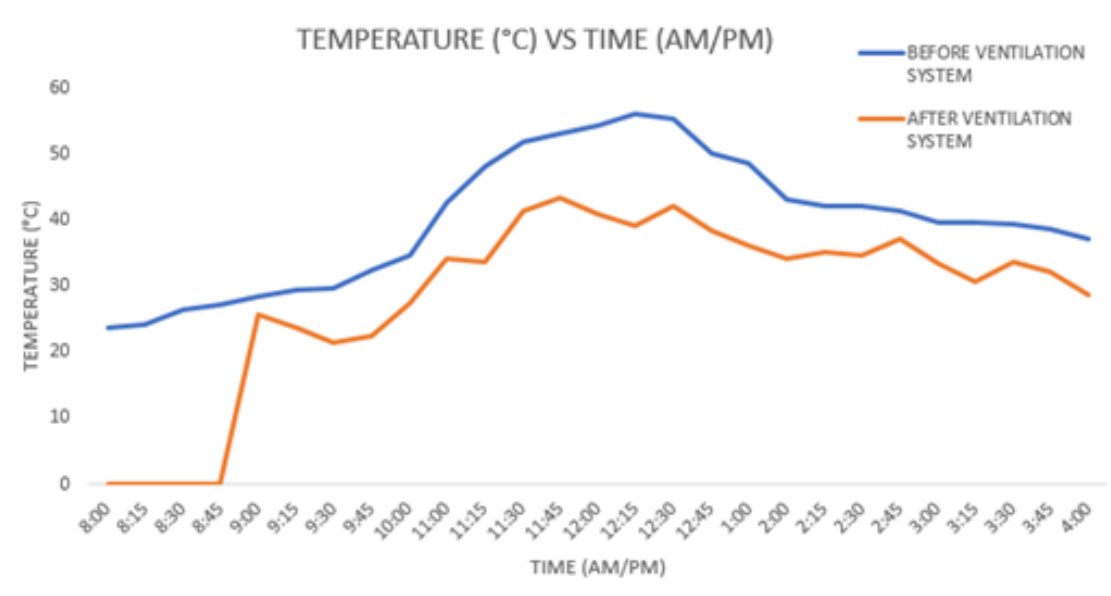

Figure 12. The graph for the temperature in the car before and after the ventilation system

\section{CONCLUSION}

This paper describes the design and implementaton of vehicle ventilation system that monitor the indoor temperature and users able to control the vehicle accesories. The system testbed was developed using NodeMCU ESP8266 microcontroller and was integrated with temperature and rain sensors. Furthermore, the microcontroller was able to control the vehicle power window remotely. This was done by integrating the testbed with the network module so that it can comunicate to the Firebase cloud service. A mobile IoT plarform had been developed to ease the users in monitoring and controlling the vehicle ventilation system. This paper suggests a future work by improving the vehicle ventilation system such as by adding and analytics module to act upon the temperature reading by the sensors, rather than manually control by the users which prone to security break. Hence, additional security features is also suggested to be added.

\section{REFERENCES}

[1] Sachin Kumar, et al., "Internet of Things is a revolutionary approach for future technology enhancement: a review," Journal of Big Data, vol. 6, pp. 1-21, 2019.

[2] Noura, M., Atiquzzaman, M. \& Gaedke, M., "Interoperability in Internet of Things: Taxonomies and Open Challenges," Mobile Network Application, vol. 24, no. 3, pp. 796-809, 2019.

[3] IoT application areas. https://iot-analytics.com/top-10-iot-project-application-areas-q3-2016/ Accessed 8 Apr 2020.

[4] S. Wadhwani, U. Singh, P. Singh, and S. Dwivedi, "Smart Home Automation and Security System using Arduino and IOT," Int. Research Journal of Engineering and Technology (IRJET), vol. 5, no. 2, pp. 1357-1359, 2018.

[5] Sharmad Pasha, "Thingspeak Based Sensing and Monitoring System for IoT with Matlab Analysis," International Journal of New Technology and Research (IJNTR), vol. 2, no. 6, pp. 19-23, 2016.

[6] Tolga Kiliç, and Esra Bayir, "An Investigation on Internet of Things Technology (IoT) In Smart Houses," Int. Journal of Engineering Research and Development, vol. 9, pp. 197-206, Dec 2017.

[7] S. A. Çeltek and H. Soy, "An application of building automation system based on wireless sensor/actuator networks," 2015 9th International Conference on Application of Information and Communication Technologies (AICT), Rostov on Don, pp. 450-453, 2015.

[8] N. A. Wahab, et al., "Performance of Environmental and Energy Audit for Manufacturing Industrial Buildings," Indonesian Journal of Electrical Eng. and Computer Science (IJEECS), vol. 12, no. 2, pp. 534 541, November 2018.

[9] S. Chaudhury, D. Paul, R. Mukherjee and S. Haldar, "Internet of Thing based healthcare monitoring system," 2017 8th Annual Industrial Automation and Electromechanical Engineering Conference (IEMECON), Bangkok, pp. 346-349, 2017.

[10] P. Visconti, et al. "IoT-oriented software platform applied to sensors-based farming facility with smartphone farmer app," Bulletin of Electrical Engineering and Informatics (BEEI), vol. 9, no. 3, pp. 1095-1105, June 2020.

[11] Nahla Abdul Jalil Salih1, Ihsan Jabbar Hasan2, Nadhir Ibrahim Abdulkhaleq3, "Design and implementation of a smart monitoring system for water quality of fish farms," Indonesian Journal of Electrical Engineering and Computer Science (IJEECS), Vol. 14, no. 1, pp. 44-50, April 2019.

[12] J. Van De Moosdijk and D. Visser, "Car security : remote keyless 'entry and go" Revision 232, June, 2009.

[13] Stephen Mason, Barrister "Vehicle remote keyless entry systems and engine immobilisers: Do not believe the insurer that this technology is perfect," Computer Law \& Security Review, vol. 28, pp. 195-200, 2012.

[14] R. Agarwal and P. Boominathan, "Vehicle Security System Using IoT Application," International Research Journal of Engineering and Technology (IRJET), vol. 5, no. 4, pp. 910-912, April 2018. 
[15] T. C. Leelavathi, B. G. Shivaleelavathi, and B. Shubha, "IoT for Smart Car using Raspberry PI," International Research Journal of Engineering and Technology (IRJET), vol. 3, no. 6, pp. 1376- 1379, June 2016.

[16] H. Rathod, et al., "Vehicular Security using IOT," International Journal of Science and Research (IJSR), vol. 6, no. 5, pp. 2664-2666, May 2017.

[17] T. Saleh, M. Raisuddin Khan, M. Bhuiyan, M. A. Ali, A. Mannan, and M. Latief, "Remote Interior Temperature Control of Parked Vehicles," Advanced Materials Research, vol. 1115, pp. 494-498, 2015.

[18] S. Kumar Reddy Mallidi and V. V. Vineela, "IoT Based Smart Vehicle Monitoring System," International Journal of Advanced Research in Computer Science, vol 9, no. 2, pp.738-741, March-April 2018.

[19] R. S. M. Joshitta and L. Arockiam, "Security in IoT Environment : A Survey," International Journal of Information Technology and Mechanical Engineering, vol. 2, no. 7, pp. 1-8, 2016.

[20] R. Dorothy and S. Sasilatha, "Smart Grid Systems Based Survey on Cyber Security Issues," Bulletin of Electrical Engineering and Informatics (BEEI), vol. 6, no. 4, pp. 337-342, December 2017.

[21] B. G. Girish, A. D. Gowda, H. Amreen, and K. M. A. Singh, "IOT based security system for smart vehicle," International Research Journal of Engineering and Technology(IRJET), vol. 5, no. 5, pp. 2869-2874, May 2018.

[22] Prachi Bhure, Naziya Pathan and Mr. Shyam Dubey, "Android Based Automation System for the next Generation of Technology using Wi-Fi," International Journal of Science Technology \& Engineering (IJSTE) , vol. 3, no. 5, pp. 1-6, 2016.

[23] V. K. Upadhye, "Remote Control of Home Appliances with Smart Energy Efficient Model Using Android Application Based on Raspberry Pi Embedded Linux Board," International Research Journal of Engineering and Technology (IRJET), vol. 4, no. 6, pp. 1640-1646, June 2017.

[24] Salman Ali Khan, Arhsad Farhad, Muhammad Ibrar, Muhammad Arif, "Real Time Algorithm for the Smart Home Automation Based on the Internet of Things," International Journal of Computer Science and Information Security (IJCSIS), vol. 14, no. 7, pp. 94-99, 2016.

[25] I. A. Salami, et al. "Intelligent flood disaster warning on the fly: developing IoT-based management platform and using 2-class neural network to predict flood status," Bulletin of Electrical Engineering and Informatics (BEEI), Vol. 8, no. 2, pp. 706-717, June 2019.

\section{BIOGRAPHIES OF AUTHORS}

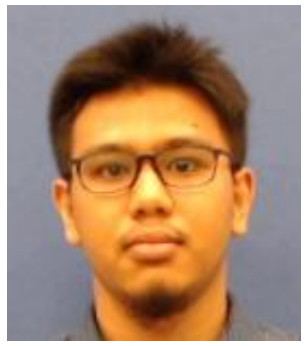

Amirun Murtaza Abd Jalil obtained the B. Eng. degree in Electrical Engineering from Universiti Teknologi MARA, Shah Alam in 2020. From 2020 until now, he is with electrical and electronic manufacturing company at Wistron Technology (Malaysia) Sdn Bhd, as Engineer (A2). He is involved with ICT test program development and cooperates with ICT fixture suppliers to solve fixture problems. His research interests are in ICT competencies and role of ICT in daily life, system performance analysis, theory of computation, and wireless communication.

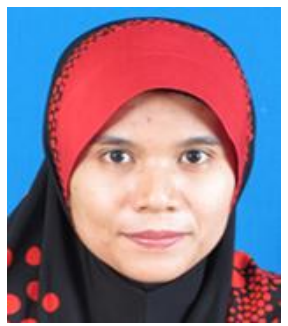

Roslina Mohamad obtained the B. Eng. degree in Electrical Engineering and M. Eng. Science degree from Universiti Malaya, Kuala Lumpur in 2003 and 2008 respectively. She received the $\mathrm{PhD}$. degree in Aerospace Engineering from Universiti Putra Malaysia, in 2016. From 2006 until now, she is with Faculty of Electrical Engineering, Universiti Teknologi MARA, as a senior lecturer. She has been appointed as a Head of Computer Engineering Studies at the same institution since 2018. Her research interests are in computing algorithm and digital signal processing for deep space communication, channel coding, theory of computation, and wireless communication.

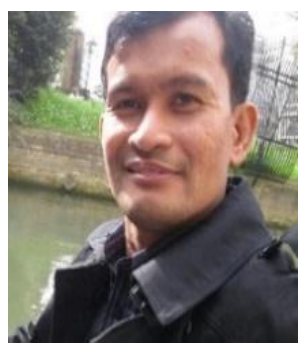

Nuzli Mohamad Anas (SM'14) received his B.Eng. and M.Eng. in electrical engineering from the Universiti Teknologi Malaysia, in 2000 and 2013, respectively. From 2008, He works as Senior Researcher at Wireless Communication Lab in MIMOS Berhad. He is currently pursuing his $\mathrm{PhD}$ in Computer and Communication System Engineering at Universiti Putra Malaysia. His research interest in the areas of wireless mobile communications and signal processing, especially on cognitive radio and physical-MAC layer communication design. 


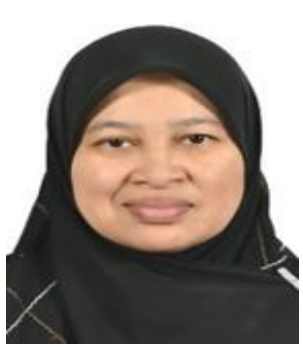

Murizah Kassim is currently working as senior lecturer at Faculty of Electrical Engineering, Universiti Teknologi MARA, Shah Alam, Selangor. She received her PhD in Electronic, Electrical and System Engineering in 2016 from the Faculty of Built Environment and Engineering, Universiti Kebangsaan Malaysia (UKM), Malaysia. She has published many papers related to computer network, Internet of Things (IoT), Web and mobile development applications research. She has experienced about 19 years in technical team at the Centre for Integrated Information System, UiTM Shah Alam. She is also the member of Enabling Internet of Things Technologies (EIIoTT) research group UiTM. She joined the academic since January 2009 and currently member of IEEE, IET, IAENG and IACSIT organization.

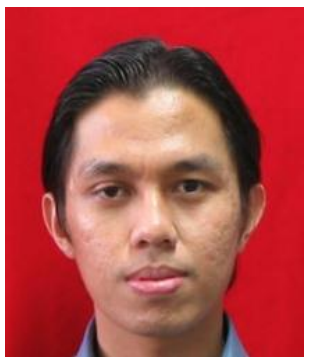

Saiful Izwan Suliman is a senior lecturer at the Faculty of Electrical Engineering, Universiti Teknologi MARA (UiTM), Malaysia. He obtained 1st class degree in Artificial Intelligence in 2002 and Master of Science (Electrical Engineering) from UiTM in 2006. His Phd was awarded by The University of Nottingham, UK in 2015. His research interest is mainly in the area or artificial intelligence, optimization and pattern recognition algorithm, metaheuristic approach, frequency bandwidth spectrum and power system operations. He has published papers in many international conferences as well as reputable journals. $\mathrm{He}$ is a certified Professional Technologist and Chartered Engineer (CEng) with IET, UK. He is currently the head of ICT Unit, Institute of Research Management and Innovation at UiTM 